\title{
The development of a healthy eating indicator shopping basket tool (HEISB) for use in food access studies-identification of key food items
}

\author{
AS Anderson 1,* , J Dewar ${ }^{1}$, D Marshall ${ }^{2}$, S Cummins ${ }^{3}$, M Taylor $^{2}$, J Dawson ${ }^{2,4,5}$ \\ and L Sparks ${ }^{4}$ \\ ${ }^{1}$ Centre for Public Health Nutrition Research, Ninewells Medical School, University of Dundee, Dundee DD 1 \\ 9SY, UK: ${ }^{2}$ Management School and Economics, University of Edinburgh, William Robertson Building, 50 \\ George Square, Edinburgh EH8 9JY, UK: ${ }^{3}$ Department of Geography, Queen Mary College, University of \\ London, Mile End Road, London E1 4NS, UK: ${ }^{4}$ Institute for Retail Studies, University of Stirling, \\ Stirling FK9 4LA, UK: ${ }^{5}$ ESADE, Av. Pedralbes 60, 08034 Barcelona, Spain
}

Submitted 31 May 2006: Accepted 15 February 2007: First published online 18 June 2007

\begin{abstract}
Objectives: To develop an objective, nutrient-based, healthy eating indicator shopping basket (HEISB) tool for use in studies of access to healthy food.

Design: Tool development used a literature search to identify previous practice, web information on current definition of healthy foods by the UK Food Standards Agency, and population-based dietary surveys to identify culturally acceptable foods. These findings were then appraised with respect to practical fieldwork considerations.

Setting: The review took account of surveys undertaken in a range of geographical areas.

Results: Previous tools have varied in the foods selected and the rationale for inclusion. Most have considered nutritional composition but no systematic definition has been used and foods have been subjectively classified as 'less healthy' or 'more healthy'. Recent UK work on nutrient profiling enabled individual food items to be objectively assessed for inclusion. Data from national food surveys enabled commonly consumed and culturally acceptable foods to be identified. Practical considerations included item use in meals, convenience, price, and fieldwork constraints. Other issues including health and price discriminators as well as regional preferences were considered. The final HEISB tool comprised 35 items within the following categories - 17 from fruit and vegetables, nine from potatoes, bread and cereal, five from fish/meats, three from dairy, and one from fatty and sugary foods.

Conclusions: The tool provides a rational basis for examining access and availability of healthy foods in cross-sectional and longitudinal retail and consumer studies.
\end{abstract}

The Scottish diet is a major contributor to high rates of premature death from cardiovascular disease and cancer, and excess morbidity related to obesity, type 2 diabetes and dental caries ${ }^{1}$. The Scottish Diet Action Plan (SDAP) ${ }^{2}$ set out a framework for helping the population shift towards a diet high in fruits, vegetables and starchy carbohydrate foods and low in fat, sugar and salt. Within the SDAP, a wide-ranging, ambitious programme of work involving primary producers, manufacturers, retailers, caterers and community action groups was initiated. However, recent analysis of dietary data has shown little shift in nutrient intake over the last decade ${ }^{3}$ and it is now recognised that further work is needed to identify effective action for achieving dietary change (particularly within socially deprived communities).

Access to healthy food at affordable prices has been recognised as a key issue influencing food choice, nutrient intake and disease prevention strategies. Successive policy documents ${ }^{4-6}$ have identified food access as a major barrier to healthy eating within deprived communities and across remote and rural locations. These reports have highlighted the potential importance of retail-based policy initiatives ${ }^{7,8}$ to help reduce diet-related health inequalities. The issue of perceived affordability 
has not been systematically assessed, but the implication can be broadly described as competitive prices for basic healthy commodities. Access includes both physical access to retail facilities as well as access to healthy options within stores, and thus concerns both macro and micro issues for consumers.

Research in this area has ranged from small-scale work to inform local community action on food ${ }^{9}$ to more rigorous approaches undertaken by multidisciplinary academic research teams ${ }^{10}$. In recent years, much of the research has focused on the concept of 'food deserts', broadly defined as areas of relative social exclusion where people experience physical and economic barriers to accessing healthy food. Methodologies and data collection tools have varied but have generally encompassed a list of commonly consumed basic food items on which price and availability data and geographical information on local retail provision have been collected.

Considerable scepticism has been expressed over this research area. The view that there are poor urban areas where residents cannot buy affordable, healthy food has been described as a "factoid'11 (an assumption or speculation reported and repeated until considered true). Recently, White et al. ${ }^{10}$ reported results from a major, multi-level, geographical analysis of the relationship between retail food access, socio-economic position and diet, concluding that 'food deserts exist only for a minority of people who do not or cannot shop outside their immediate locality and for whom the locality suffers from poor retail provision of foods that compose a healthy diet'. In contrast, Wrigley ${ }^{12}$ highlights the economic and physical access constraints perceived by residents living in a food desert. Qualitative research suggests that 'life in a food desert' is far from a minor inconvenience; issues such as access to quality branded foods (as opposed to budget lines), easily prepared healthy foods for elderly, immobile consumers and access to stores by parents of young children and frail elderly have considerable impacts on quality of daily life ${ }^{13}$. Some communities have been so dissatisfied with local retail provision (notably poor quality, range and price of fresh fruit and vegetables) that local food co-operatives have been established. Indeed, much of the work of the (Scottish Executive-funded) Scottish Community Diet Project has been to support local food access work in deprived communities.

One of the key methodological challenges within food access research is defining which foods should be included in data collection. For decades, nutritionists have avoided the term 'healthy foods' on the grounds that there can only be 'healthy diets'. However, this approach has changed in recent years as the UK Food Standards Agency (FSA) has moved to defining 'what's a lot' and 'what's a little $^{14}$ to guide consumer decision-making when reading nutrition labels on individual foods. Furthermore, work on nutrient profiling ${ }^{15}$ by the FSA, developed specifically to guide the Office of Communications (OFCOM) in the regulation of food advertising to children, has resulted in a nutrient scoring system for individual foods. Focusing on the nutritional values of foods is a key issue for guiding data collection, but it is also important to achieve a representative selection of foods capable of formulating a diet which is deemed culturally acceptable to the population under investigation.

Within Scotland, national policy work has included both community action and partnerships with retailers ${ }^{5}$. However, a national, independent, systematic study of retail provision and data on accessibility and affordability to generate an evidence base for action on retail policy is overdue.

The aim of the present work was to identify objective nutrition criteria, cultural aspects of food selections and practical fieldwork considerations to inform the development of a healthy eating indicator shopping basket (HEISB) tool with specific reference to the Scottish Dietary Targets. The development of such a tool is a key part of projects that require cross-sectional and longitudinal assessments of access to healthy food at affordable prices.

\section{Methods}

\section{Overview}

It was recognised that a 'basket' of foods that represented all foods available for purchase or total diet requirements would exceed the parameters of the proposed tool. In this context, the tool is an indicator of 'healthy eating' selections. Tool development involved a literature search to identify previous methodologies used in food access studies, current definition of healthy foods from the FSA, and data from population-based dietary surveys on culturally acceptable (popular) foods. This information was then reviewed with respect to practical fieldwork considerations.

In order to allow some comparability with previous studies, foods selected and their nutritional dimensions were identified from published work. A literature search using Medline/PubMed, an electronic search of the FSA website and hand searches of personal collections using the terms 'food deserts', 'food poverty' and 'retail' was undertaken. Foods used in published price comparison studies were noted. The FSA website was electronically searched for advice to consumers on healthy food choices $^{14}$, nutrient profile data and nutrition information ${ }^{15}$ aimed at the public.

The UK Expenditure and Food Survey ${ }^{16}$ (previously National Food Survey) utilises data collected at household level. In 2002 the number of households surveyed in Scotland was 548 (1320 individuals), and is regarded as representative of the Scottish population. Data from the survey were analysed for frequency of food item consumption but presented problems for the current analysis 
in that data had been coded on a food group rather than a food item basis (e.g. bran-type cereals are combined with branded items such as Weetabix).

The National Diet and Nutrition Survey (2002) ${ }^{17}$ collected detailed data on food consumption using a 7-day weighed method. The sample size for Scotland was 123 adults and can therefore only indicate some broad trends. Popularity of foods was determined by the frequency of consumption weighted by the number of consumers recording these food items in the study period. Food items were excluded if consumed by less than $10 \%$ of consumers. However, it was recognised that the use of discriminator items on the basis of health or regional preferences may necessitate a lower consumption cut-off for these items.

In addition, a review of Scottish data ${ }^{18}$ obtained from Taylor Nelson Sofres provided information on food presentation (e.g. cook chill) and preparation (e.g. cooking methods).

\section{Practical considerations}

Foods for meals requiring minimal skills and facilities (e.g. breakfast, sandwich lunch, main meal) were selected for inclusion in the tool and included convenience foods such as frozen peas. Drinks (e.g. cola drinks) and snacks (e.g. crisps) were omitted except where these would fit the 'five portions of fruit and vegetables per day criterion'. Previous workers in the field advised about practical issues for data collection.

\section{Results}

\section{Nutrition dimensions of tools used in food access studies}

Many studies of food access have used a food basket methodology for data collection. The contents of these baskets have been very wide ranging and not necessarily based on desirable nutrition content. For example, in Australia, the Queensland Healthy Food Access Basket ${ }^{19}$ utilised an assessment tool that reflected commonly available and popular foods such as sausages. The tool assessed the availability and cost of a basket designed to meet $70 \%$ of the nutritional requirements and $95 \%$ of the estimated energy requirements of a family of six for two weeks. The challenge of how to meet the remaining 30\% of nutritional requirements within 5\% of energy was not addressed.

In the USA, food basket work is used to inform the implementation of food and health policy. The US Department of Agriculture's Thrifty Food Plan (TFP) ${ }^{20}$ represents a set of market baskets, each applicable to one of 12 age-gender groups, based around a single week's menu and recipes. The 86 -item TFP market food basket is designed to reflect current dietary recommendations, actual consumption patterns, food composition data, and food prices. With a focus on low-income groups and food equity, prices collected are always for the least expensive items. Consequently, the TFP serves as a national standard for a nutritious diet at minimal cost and is used as the basis for food stamp allocations.

The US work contrasts with that of the UK, which has tended to be used for academic debate rather than policy purposes. In 1990, Mooney ${ }^{21}$ reported whether foods and diet being promoted by the local Food Health Policy in the London borough of Camden were affordable and available to all sections of the community. The price and availability of two lists of 30 foods were compared within and between two contrasting socio-economic areas of London. List A comprised a recommended type diet (based on the foods eaten by a group of people who achieved the long-term guidelines of the National Advisory Committee on Nutrition Education $(\mathrm{NACNE})^{22}$ ) and List $\mathrm{B}$ was based on the diet of low-income group D (using National Food Survey categories) and did not meet NACNE or local dietary guidelines.

Sooman $e t a .^{23}$ carried out a small exploratory study of two socially contrasting and non-contiguous localities in Glasgow using a shopping basket approach of 29 foods 'which people are encouraged to eat more of' and a list of foods of 'which people are being encouraged to eat less' based on information from the Health Education Authority (1991).

Piachaud and $\mathrm{Webb}^{24}$ carried out a price survey of 23 items based on a list of 'the most popular and best known basic foods' so that a variety of different items were represented. The list did not include items where quality was highly variable or seasonal items or where there were obvious difficulties with comparability. There are no indications that a nutritional dimension was included, although the authors note that they included 'unhealthy' items such as jam tarts, steak and kidney pie and rice pudding because they did not wish the list to be too prescriptive.

Donkin et $a l^{25}$ undertook survey work in two contiguous London wards, basing basket selections on foods that contributed to a 'healthy diet', while reflecting ethnic preferences and variations in shopping practices, different household size, local tastes and normal eating patterns, and area income levels within study areas. Four different food assessment lists - reflecting white UK/Irish, Caribbean, African and Gujarati Hindu food preferences were compiled to represent a 'typical, though not prescriptive' range of foods which would be bought by the majority of a given ethnic group. Each ethnic group food list contained approximately 40 foods, amounting to 71 foods in total given the overlap of several foods in each diet. Not all foods which could contribute to a healthy, ethnically sensitive diet could be included and consequently a specific list of foods was drawn up focusing on main meal items.

A study by Cummins and Macintyre ${ }^{26}$ examining the price and availability of food in the Greater Glasgow 
Health Board area used a 57-item food list derived from the Family Budget Unit's 'modest but adequate' diet $^{27}$ which, in total, takes account of recommended daily allowances of nutrients, meets guidelines for healthy eating, and was then based on current food consumption patterns. The assessment tool also included 'less healthy items' such as such as sausages, baked goods, streaky bacon, cola, chocolate, butter and whole milk.

White et $a l .{ }^{10}$ undertook a study of retail food access in Newcastle using 33 commonly consumed 'popular' foods (using data derived from locally based food studies work) and taking account of meal structure, including 'healthy' and 'less healthy' foods and a range of fruits and vegetables. Healthier foods that were typically eaten by Newcastle residents and had comparable 'less healthy' options which were also eaten at similar frequency were included (e.g. semi-skimmed milk and whole milk) and other similar foods that were perceived as being 'healthy' (e.g. low-fat yoghurt) or 'less healthy' (e.g. crisps) were included. The selected foods comprised four categories: 'fresh fruit and vegetables', 'Healthier choices', 'Less healthier choices' and 'Neutral health choices'.

The UK studies outlined above showed considerable overlap in the number and type of items used in their respective tools. Foods that were utilised in at least three of the six identified studies were used as the starting point for the current tool in order to allow some comparison with previous work. A total of 31 foods were identified and categorised into five groups as follows: 12 (40\%) from fruits and vegetables; six (19\%) from potatoes, bread and cereals; seven (23\%) from meat and alternatives; four (13\%) from dairy foods; and two (6\%) from fats and sugars (see Table 1).

\section{Definition of bealtby foods witbin a bealtby diet}

After identifying commonly used food items from previous studies as the starting point, an objective nutrition criterion was then applied. The National Food Guide (Balance of Good Health) ${ }^{28}$ was used as an initial guide to direct overall food balance in the tool. Table 2 describes the recommended relative daily consumption for each food group by portion frequency. The proportions clearly illustrate that the bulk of an individual's diet should be derived from starchy foods, fruits and vegetables. However, little information is provided on the selection of individual foods, although broad advice is provided, such as consuming low-fat versions where such a choice exists.

Furthermore, choosing a variety of foods across and within food groups is thought to improve nutritional adequacy $^{30}$. For example, within the fruits and vegetables group, current five-a-day ${ }^{31}$ messages promote variety in intake in order to achieve consumption of a wide range of bioactive substances.

The FSA provides specific guidance on nutrient composition of healthful foods to assist the consumer to interpret nutrient information on labels ${ }^{14}$. Information on fat, saturates, salt and sugar is described as 'a little' or 'a lot' (Table 3) and can be used to define limits for healthful and less healthful items.

Recent work by the FSA on nutrient profiling (specifically to help guide OFCOM in regulation procedures related to food advertising directed at children) has created a model for scoring the overall nutrient profile for individual foods and drinks. The model 'assesses foods on the basis of a wide range of nutrients (including energy, saturated fat, sugar and salt; as well as fibre, protein and fruit and vegetables). It uses a "scoring" system to rate the overall balance of nutrients in a food and in so doing identifies foods high in fat, salt or sugar while recognizing the important contribution of fruit, vegetables and cereal, meat and dairy based products to a balanced diet ${ }^{28}$.

This model allows each food to be scored and assessed for overall nutrient profiles acting as a proxy for definition of a healthful food and can be applied to individual food within an assessment tool. Foods which score greater than 4 (e.g. white bread, cornflakes, sausages, sugar, whole milk, cheddar cheese) are classified as 'high in saturates, salt and sugar' and were excluded from the initial tool, leaving 25 foods.

Table 1 Common Items used in UK 'healthy eating' retail studies

\begin{tabular}{lccc}
\hline Fruits and vegetables & Potatoes, bread and cereals & Meat and alternatives & Dairy \\
\hline Cabbage & White bread & Eggs & Milk (whole) \\
Carrots & Wholemeal bread & Beef mince & Milk (semi-skimmed) \\
Onions & Potatoes & Sugar & Yoghurt (fruit) \\
Frozen peas & Cornflakes & Chicken & Cheddar cheese \\
Tomatoes (canned) & Weetabix & Fish fingers & Cod fillets \\
Tomatoes & Spaghetti & Baked beans & \\
Apples & & & \\
Bananas & & & \\
Oranges & & \\
Orange juice & & \\
Lettuce & & \\
Cucumber & & \\
\hline
\end{tabular}

${ }^{*}$ PUFA - spread high in polyunsaturated fatty acids. 
Table 2 Recommended overall food balance - portion frequency

\begin{tabular}{lll}
\hline Food group & Daily recommendation & \multicolumn{1}{c}{ Additional messages } \\
\hline $\begin{array}{l}\text { Fruit and vegetables } \\
\text { Bread, cereal and potatoes }\end{array}$ & $\begin{array}{l}\text { Plenty (5-9 measures) } \\
\text { Plenty (5-14 measures) }\end{array}$ & $\begin{array}{l}\text { Eat a wide variety. Avoid rich sauces and added sugar } \\
\text { Try to eat wholemeal, wholegrain, brown or high-fibre versions. } \\
\text { Avoid fried versions. Avoid adding too much fat or rich sauces } \\
\text { and dressings }\end{array}$ \\
$\begin{array}{l}\text { Meat, fish and alternatives } \\
\text { Milk and dairy foods }\end{array}$ & $\begin{array}{l}\text { Moderate (2-3 measures) } \\
\text { Fatty and sugary foods }\end{array}$ & $\begin{array}{l}\text { Moderate (2-3 measures) } \\
\text { Choose lower-fat version and cook without added fat }\end{array}$ \\
& Eand drink sparingly & $\begin{array}{l}\text { Limit consumption. Choose low-fat/reduced-sugar options when } \\
\text { possible. Sugary foods \& drinks should be eaten mainly at mealtimes }\end{array}$ \\
\hline
\end{tabular}

Source: Adapted from The Balance of Good Health: Information for Educators and Communicators ${ }^{28}$ and The Little Book of White Lies ${ }^{29}$.

Table 3 Food Standards Agency's definition ${ }^{14}$ of amounts of key nutrients in foods

\begin{tabular}{llll}
\hline Nutrient & \multicolumn{1}{c}{ 'A little' } & \multicolumn{1}{c}{ 'Moderate' } & \multicolumn{1}{c}{ 'A lot } \\
\hline Total fats & $\leq 3 \mathrm{~g} / 100 \mathrm{~g}$ & $3-20 \mathrm{~g} / 100 \mathrm{~g}$ & $>20 \mathrm{~g} / 100 \mathrm{~g}$ \\
Saturated fat & $\leq 1 \mathrm{~g} / 100 \mathrm{~g}$ & $1-5 \mathrm{~g} / 100 \mathrm{~g}$ & $>5 \mathrm{~g} / 100 \mathrm{~g}$ \\
Sodium & $\leq 0.1 \mathrm{~g} / 100 \mathrm{~g}$ & $0.1-0.5 \mathrm{~g} / 100 \mathrm{~g}$ & $>0.5 \mathrm{~g} / 100 \mathrm{~g}$ \\
Sugar & $\leq 2 \mathrm{~g} / 100 \mathrm{~g}$ & $2-10 \mathrm{~g} / 100 \mathrm{~g}$ & $>10 \mathrm{~g} / 100 \mathrm{~g}$ \\
\hline
\end{tabular}

\section{Definition of culturally acceptable foods}

To identify possible items for further inclusion, a range of foods meeting nutrient score definitions was then generated. In order to further refine which foods might be selected for the final tool, the popularity of each item was identified.

Scottish data from Taylor Nelson Sofres on foods eaten by meal and by purchase were reviewed by Blades ${ }^{18}$. Of the foods selected on nutritional grounds, it was noted that consumption of chilled ready-meals was $4 \%$ higher in Scotland than in the rest of the UK. Other differences showing that Scottish cuisine includes more frying, more meals eaten outside the home, and a lower popularity of beef were less relevant in the current 'healthful' basket context. It should be noted that lean beef mince was included in the tool.

Finally, positive aspects of the Scottish dietary targets (e.g. items which are recommended for increase such as fish and wholemeal products) and perceived 'traditional, cultural' Scottish foods (e.g. porridge, oatcakes and salmon) were also considered.

\section{Practical considerations}

Previous fieldwork by Cummins ${ }^{32}$ indicated that details on brand name, weight and quality of (a maximum) of 30 to 35 foods could be collected in a $30-45 \mathrm{~min}$ in-store retail assessment. It was also noted that certain food items are particularly useful at indicating pricing policy (e.g. wholemeal bread). Further suggestions to add 'healthy food discriminators' (e.g. brown rice) were considered.

\section{The HEISB tool}

The HEISB tool is therefore largely based on food items commonly used in previous work that met nutrient pro- file guidelines ( 25 foods) with the following amendments: eggs were excluded to decrease the number of foods in the meats/fish group. Four items which were suitable for inclusion were substituted: broccoli was used instead of cabbage to allow frozen formats to be used; canned sweet corn replaced canned tomatoes to avoid duplication (raw tomatoes were included); haddock fillet replaced cod based on Scottish purchase data; fish fingers were replaced by salmon fillet to fit with Scottish diet targets and preferences. In addition, berries (frozen) were added as one of the few fruits grown in Scotland and porridge as a widely known Scottish cereal.

Additions to the tool based upon convenience included oven chips, canned pineapple and a ready meal (Birds Eye $^{\mathrm{TM}}$ Lasagne). Two items (skimmed milk and brown rice) were added in as health discriminators. No additional foods were added as price discriminators but key items for this category were wholemeal bread and orange juice. Finally, grapes, red peppers, brown rolls and white rice were added in order to increase variety within the fruits and vegetables group, and the bread, cereals and potatoes group, respectively.

Table 4 provides a list of foods included and the rationale for inclusion. The final HEISB tool comprised 35 foods. These proportions allow for considerable variety within the fruits and vegetables group, and the bread, cereals and potatoes group, respectively, with less emphasis on meats (but relying on leaner varieties and fish), emphasis on low-fat dairy products and minimal input from fats and sugar groups.

\section{Discussion}

Current nutrition policy objectives are to achieve longterm improvements in the diet of the UK population, while reducing inequalities by enabling and encouraging the disadvantaged and vulnerable to improve their diets $^{31}$. Ensuring that basic healthful foods are available at affordable prices, in acceptable forms (e.g. fresh as well as frozen), with sufficient variety in local retail facilities, is considered an important part of promoting healthy food choices. Understanding food access at local and national levels is therefore important. 
Table 4 Final components of HEISB tool with reasons for item selection

\begin{tabular}{|c|c|c|c|c|c|c|c|c|c|}
\hline Food group & Food item & $\begin{array}{l}\text { Frequently used } \\
\text { in previous models }\end{array}$ & $\begin{array}{l}\text { Nutrient } \\
\text { score }^{*}\end{array}$ & $\begin{array}{c}\text { NDNS } \\
\text { (\% consumers) }\end{array}$ & Scottish & Convenience & Healthful & Price & $\begin{array}{c}\text { To increase } \\
\text { variety in food group }\end{array}$ \\
\hline \multirow{9}{*}{ Bread, cereal and potatoes $(n=9)$} & Brown rolls & & -2 & 12 & & & & & yes \\
\hline & Porridge oats & & -4 & 9 & yes & & & & \\
\hline & Potatoes & yes & -2 & 94 & & & & & \\
\hline & Potatoes - oven chips & & 0 & 24 & & yes & & & \\
\hline & Rice - brown & & -2 & 1 & & & yes & & \\
\hline & Rice - white & & 0 & 21 & & & & & yes \\
\hline & Spaghetti (dry) & yes & -5 & 39 & & & & & \\
\hline & Weetabix & yes & -6 & 13 & & & & yes & \\
\hline & Wholemeal bread & yes & -3 & 23 & & & & yes & \\
\hline \multirow[t]{17}{*}{ Fruits and vegetables $(n=17)$} & Apples & yes & -5 & 28 & & & & & \\
\hline & Bananas & yes & -1 & 48 & & & & & \\
\hline & Grapes & & -2 & 11 & & & & & yes \\
\hline & Oranges & yes & -6 & 13 & & & & & \\
\hline & Orange juice & yes & -4 & 20 & & & & yes & \\
\hline & Pineapple (canned) & & -3 & 6 & & yes & & & \\
\hline & Berries (frozen) & & -5 & 11 & yes & & & & \\
\hline & Baked beans & yes & -6 & 31 & & & & & \\
\hline & Broccoli & $t$ & -10 & 8 & & & & & \\
\hline & Carrots & yes & -8 & 20 & & & & & \\
\hline & Cucumber & yes & -5 & 36 & & & & & \\
\hline & Lettuce & yes & -6 & 36 & & & & & \\
\hline & Onions & yes & -5 & 13 & & & & & \\
\hline & Peas (frozen) & yes & -14 & 20 & & yes & & & \\
\hline & Peppers (red) & & -6 & 29 & & & & & yes \\
\hline & Sweet corn (canned) & $t$ & 2 & 18 & & yes & & & \\
\hline & Tomatoes (fresh) & yes & -6 & 66 & & & & & \\
\hline \multirow{3}{*}{ Dairy $(n=3)$} & Semi-skimmed milk & yes & 0 & 43 & & & & yes & \\
\hline & Skimmed milk & & -2 & 13 & & & yes & & \\
\hline & Low-fat yoghurt & yes & 0 & 14 & & & & & \\
\hline \multirow[t]{5}{*}{ Meats, fish, etc. $(n=5)$} & Beef mince (lean) & yes & 0 & 13 & & & yes & & \\
\hline & Birds Eye ${ }^{\mathrm{TM}}$ Lasagne & & 0 & unknown & & yes & & & \\
\hline & Chicken breast & yes & -4 & 18 & & & & & \\
\hline & Haddock fillets (no coating) & $t$ & -4 & 10 & yes & & yes & & \\
\hline & Salmon fillets & $t$ & -2 & 16 & yes & & & & \\
\hline Fatty and sugary foods $(n=1)$ & Low-fat PUFA spread & yes & 10 & 37 & & & & & \\
\hline
\end{tabular}


Previous tools used in retail price and availability assessments have varied in the number of items selected and the rationale for item selection. Most have considered nutritional composition, amongst various factors, but no systematic definition has been used. This paper develops and proposes a tool for such research, both in general for community and academic researchers and for specific project work undertaken in Scotland.

Previous approaches do not reflect the wide range of foods that clearly fit as part of a healthy varied diet. Within the current tool, consumption of 'less healthy' foods is assumed, but need not be part of the assessment tool as total diet is not being estimated. Overall dietary balance is defined in nutrient terms ${ }^{33}$. To translate nutritional recommendations into food choices, the FSA provides public guidance in the form of the Balance of Good Health $^{28}$ and advice on low, medium and high amounts of saturates, sugar and salt in foods. Recent work on nutrient profiling enables foods to be scored and provides an objective nutritional basis for selecting foods to be used within an assessment tool.

It is clear that a number of other factors are relevant in terms of expanding food items into dietary intake, including seasonality, consumer preference and brand popularity. In addition, for national policy purposes it appears important to identify foods that are capable of price discrimination (e.g. wholemeal bread) and foods that can be easily found and compared in terms of brand, weight and quality.

Consumers access food through the decisions made by retailers on what to stock, and personal consumer decisions on what to buy and consume. This is mediated by retailer effectiveness in distribution, supplier promotional activity, and consumer predilections and knowledge. Retailers, and their suppliers, both respond to but also shape consumer demand. Such factors need to be considered in the derivation of survey tools to measure food availability. The proposed basket not only includes elements of a common healthy diet but also attempts to survey wider aspects of healthful food choices.

Population subgroups will also be strongly influenced by cultural background, and investigations focusing on the health of black and ethnic minority groups will require specific tools to take account of the diversity of eating habits within the population under study. Likewise, regional preferences and habits may involve different food selections for the tool.

The HEISB tool provides a standardised tool for examining the price and availability of a wider range of healthy foods in the ethnic majority population. The tool is an indicator tool only. Detailed nutrient assessment would require complementary information derived from other nutritional survey methodologies such as diet diaries.

The development of this tool forms the first stage in designing a tool for examining access and availability of healthy foods in cross-sectional and longitudinal retail and consumer studies to help inform policy work in this arena. Pilot work is now being undertaken across the country in order to assess the validity and utility of the measure in a range of retail settings in urban, rural and remote regions. Specific details of unit size, format of presentation and substitute products will be derived and reported from that pilot work, providing further refinements for practical use. The tool kit has a very clearly specified set of notes for fieldworkers indicating specific products, suitable substitutes and, in the case of packaged products, specifying sizes, etc.

Details of subsequent analysis work will establish the value of the HEISB tool in informing national policy development and action planning for the promotion of healthier diets.

\section{Acknowledgements}

Sources of funding: This work was funded by the Food Standards Agency Scotland as part of a commissioned research study on 'Accessing Healthy Food: A National Assessment and Sentinel Mapping Study of Food Retailing in Scotland (S04005)'. S.C. is supported by an MRC Special Training Fellowship in Health of the Public.

Conflict of interest declaration: None.

Authorship responsibilities: A.S.A. - study design, study execution, text drafting and editing; J.D. - study execution, text drafting and editing; D.M. - study design, text drafting and editing; S.C. - study design, text drafting and editing; M.T. - study design, text drafting and editing; J.D. - study design, text drafting and editing; L.S. - study design, text drafting and editing.

Acknowledgements: Thanks to Laura Nisbet (FSAfunded PhD student, University of Edinburgh) for input on discussion and concept planning.

\section{References}

1 The Scottish Office Department of Health. The Scottish Diet Report. Edinburgh: The Scottish Office Department of Health, 1993.

2 The Scottish Office Department of Health. Scotland's Health: A Challenge To Us All. Eating for Health: A Diet Action Plan for Scotland. Edinburgh: The Scottish Office Department of Health, 1996.

3 Wrieden WL, Armstrong J, Barton KL, Peace H. A comparison of various existing surveys on food consumption in Scotland and their usefulness in measuring the Scottish Dietary Targets. Proceedings of the Nutrition Society 2005; 64: 60A.

4 Department of Health (DoH). The Food and Health Action Plan. Food and Health Problems: Analysis for Comment. London: DoH, 2003.

5 Scottish Executive. Eating for Health: Meeting the Challenge. Edinburgh: Scottish Executive, 2004.

6 Department of Health (DoH). Choosing Health: Making Healthier Choices Easier. London: DoH, 2004.

7 Department of Health (DoH). Reducing Health Inequalities: An Action Report. London: DoH, 1999. 
8 Department of Health (DoH). Report of Policy Action Team 13: Improving Shopping Access for People Living in Deprived Neighbourboods. London: DoH, 1999.

9 Coady J, O'Hara E. Five-a-day Community Project, County Durbam and Darlington: A Report for the Department of Health [online], 2002. Available at http://www.dh.gov.uk/ assetRoot/04/01/92/29/04019229.pdf. Accessed 13 February 2006.

10 White M, Bunting J, Raybould S, Adamson A, Williams L, Mathers J. Do Food Deserts Exist? A multi-level, geographical analysis of the relationship between retail food access, socio-economic position and dietary intake. Final Report to the Food Standards Agency, Project No. N09010 [online], February 2004. Available at http://www.food. gov.uk/science/research/researchinfo/nutritionresearch/ foodacceptability/n09programme/n09projectlist/n09010/ n09010r. Accessed 13 February 2006.

11 Cummins S, Macinytre S. Food deserts - evidence and assumptions in health policy making. British Medical Journal 2002; 325: 436-8.

12 Wrigley N. Food deserts in British cities: policy context and research priorities. Urban Studies 2002; 39: 2029-40.

13 Whelan A, Wrigley N, Warm C, Cannings E. Life in a food desert'. Urban Studies 2002; 39: 2083-100.

14 Food Standards Agency. 8 tips for eating well [online]. Available at http://www.eatwell.gov.uk/healthydiet/ eighttipssection/8tips/. Accessed 13 February 2006.

15 Food Standards Agency. The nutrient profiling model [online], 2 March 2006. Available at http://www.foodstandards.gov.uk/ healthiereating/advertisingtochildren/nutlab/nutprofmod. Accessed 20 April 2007.

16 Department for Environment, Food and Rural Affairs. Family Food - Report on the Expenditure \& Food Survey [online]. Available at http://statistics.defra.gov.uk/esg/ publications/efs/. Accessed 13 February 2006.

17 Hoare J, Henderson H, Bates CJ, Prentice A, Birch M, Swan $\mathrm{G}$, et al. The National Diet and Nutrition Survey: Adults aged 19 to 64 years. Summary Report. London: The Stationery Office, 2004.

18 Blades M. An examination of the Scottish diet. Nutrition and Food Science 2004; 34: 246-52.

19 Burns CM, Gibbon P, Boak R, Baudinette S, Dunbar JA. Food cost and availability in a rural setting in Australia. Rural and Remote Health 2004; 4: 311[online]. Available at http://rrh.deakin.edu.au. Accessed 4 July 2005.
20 Cohen B. USDA Community Food Security Assessment Toolkit [online], 2002. Available at http://www.ers.usda. gov/publications/efan02013. Accessed 23 June 2005.

21 Mooney C. Cost and availability of healthy foods choices in a London Health District. Journal of Human Nutrition and Dietetics 1990; 3: 111-20.

22 National Advisory Committee on Nutrition Education. $A$ Discussion Paper on Proposals for Nutrition Guidelines for Health Education in Britain. London: The Health Education Council, 1983.

23 Sooman A, Macintyre S, Anderson A. Scotland's health - a more difficult challenge for some? The price and availability of healthy foods in socially contrasting localities in the West of Scotland. Health Bulletin 1993; 51: 276-84.

24 Piachaud D, Webb J. The Price of Food: Missing Out on Mass Consumption. London: STCERD London School of Economics, 1996.

25 Donkin AJM, Dowler EA, Stevenson SJ, Turner SA. Mapping access to food in a deprived area: the development of price and availability indices. Public Health Nutrition 1999; 3: 31-8.

26 Cummins S, Macintyre S. A systematic study of an urban foodscape: the price and availability of food in Greater Glasgow. Urban Studies 2002; 39: 2115-30.

27 Nelson M, Mayer A, Manly P. The food budget. In: Bradshaw J, ed. Budget Standards for the UK. Aldershot: Avebury, 1993; 35-64.

28 Food Standards Agency (FSA). The Balance of Good Health: Information for Educators and Communicators. London: FSA, 2001.

29 Health Education Board for Scotland (HEBS). The Little Book of White Lies. Edinburgh: HEBS, 2002.

30 Krebs-Smith SM, Guthrie HA, Krebs-Smith J. The effects of variety in food choices on dietary quality. Journal of the American Dietetic Association 1987; 87: 897-903.

31 Food Standards Agency Scotland. Food Standards Agency Scotland's Diet and Nutrition Strategy: Our Role in Implementing the Scottish Diet Action Plan 2003-2006. Edinburgh: The Stationery Office, 2003.

32 Cummins S. Socio-spatial variations in the price and availability of food and their implications for bealthy eating. PhD thesis, University of Glasgow, 2001.

33 Department of Health. Dietary Reference Values for Food Energy and Nutrients for the United Kingdom: Report of the Panel on Dietary Reference Values, Committee on Medical Aspects of Food Policy. London: HMSO, 1991. 